\title{
Augmented reality application for chemical bonding based on android
}

\author{
Alexander Setiawan, Silvia Rostianingsih, Timotius Reinaldo Widodo
}

Informatics Department, Petra Christian University Surabaya, Indonesia

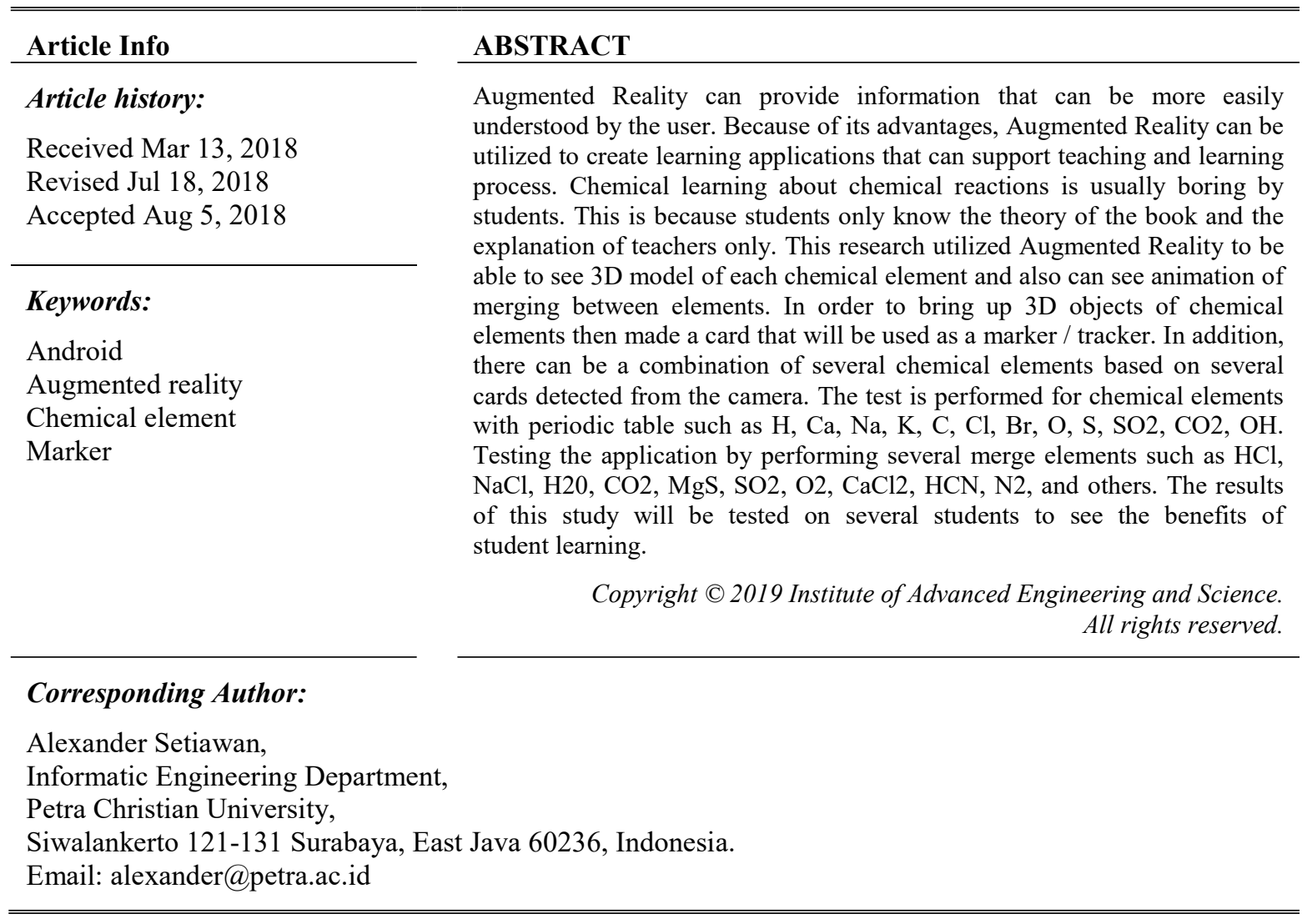

\section{INTRODUCTION}

One interesting technology that can be developed in mobile applications is Augmented Reality. Augmented Reality is a technology that combines two-dimensional or three-dimensional virtual objects into a real three-dimensional environment then projecting these virtual objects in real time. Augmented Reality has a lot of benefits that can be applied in various fields, including health, manufacturing and reparations, entertainment, military, and education. Augmented Reality can provide a picture or information that can be more easily understood by the user. Because of its advantages, Augmented Reality can be utilized to create learning applications that can support teaching and learning process.

Chemical learning about chemical reactions is usually boring by students. This is because students only know the theory of the book and the explanation of teachers only. By making applications that utilize Augmented Reality, students are expected to be more interested and enthusiastic to learn chemical reactions. The use of Augmented Reality in learning has been tested on several school materials such as chemistry, mathematics $[1,2]$. It was also tested on several college materials such as informatics and architecture [3, 4]. The study concluded that Augmented Reality helps student learning more effectively and students also positively argue with the application. In addition, several other studies also use this application Augmented Reality to be able to see 3D models of each chemical element and also can see animation merging between elements. 


\section{RELATED RESEARCH}

\subsection{Augmented reality}

Augmented Reality (AR) is a variation of the Virtual Environment (VE) or commonly known as Virtual Reality [5]. Augmented reality can be defined as able to deal with the new information immediately direct or indirect therefore influence the physical real-world environment has been enhanced/augmented were by adding virtual computer-generated information to it [6,7]. Also, the AR is defined by Azuma in 1997 [8]. He indicates that the AR is not only restricted to the technical hardware whereas it brings the real and virtual items together in a real environment. In addition, it records the real and virtual objects together and then runs jointly in real time in three dimensions [9].

\subsection{Augmented reality component}

Some of the components required in the manufacture and development of Augmented Reality applications are follows hardware, software, marker [10]. The marker is physical objects or places where virtual and real environments merge. It is identified as a place to bring up digital information. The use of markers in Augmented reality aplications depends on the libraries used in their development. The examples of marker can be seen on Figure 1.

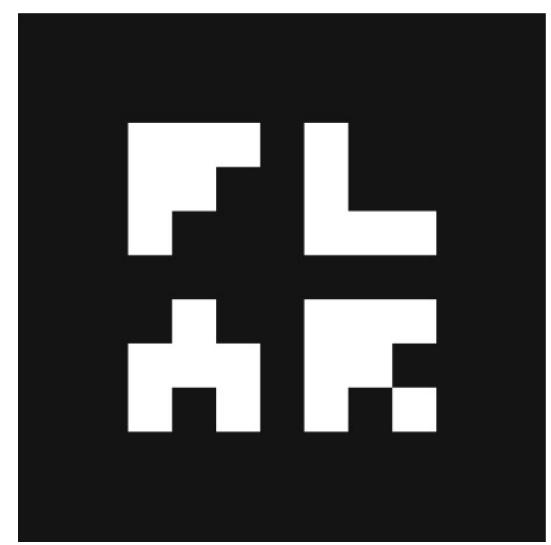

Figure 1. The example of marker

Source: http://www.bitrebels.com/wp-content/uploads/2010/01/armarker.png

\subsection{Android}

Android provides an open platform for developers to create their own applications. Initially developed by Android Inc. For its development, formed the Open Handset Alliance (OHA), a consortium of 34 hardware companies, software companies, and telecommunications, including Google, HTC, Intel, Motorola, Qualcomm, T-Mobile, and NVIDIA. [11]. The open nature of Android that has made a large number of communities have sprung up application developers to use Android as the basis for the project of making applications, by adding new features for Android on the devices officially released by using another operating system. [12]. Android is a software stack for mobile devices that includes an operating system, middleware and key applications. The Android SDK provides the tools and APIs necessary to begin developing applications on the Android platform using the Java programming language [13].

\subsection{AJAX}

AJAX is a technique to make the display more quickly and dynamically. AJAX allows the display can perform updates by exchanging small amounts of data. This will increase interactivity, speed, and usability [14].

AJAX is a combination of:

a. DOM accessed with a client-side scripting language to dynamically display and interact with information displayed

b. Objects from Microsoft XMLHTTP or XMLHttpRequest more commonly implemented in some browsers. This object is useful as a vehicle exchange of data asynchronously with the web server. In some frameworks AJAX, HTML IFrame element preferred over XMLHTTP or XMLHttpRequest to exchange data with the web server. Webserver is a provider of a web service through HTTP or HTTPS 
protocol. Webserver system will be accessible through Location Based Service. Webserver to be used is already integrated with Apache PHP components [15]

c. XML is commonly used as a transfer document, although other formats are also possible, such as HTML, plain text. XML is recommended in the use of AJAX techniques for handling ease of access by using DOM

d. JSON can be an alternative choice as a transfer document, given JSON is JavaScript itself making handling easier

\section{ANALYSIS AND RESULTS}

3.1. Analysis of Needs

a. Make Android based mobile application that can be easily accessed by the user so as to facilitate the recognition process through the application of chemical bonding

b. In this application the necessary features to provide marker and image so that the user can learn and remember more about the learning through information given and practical for use on mobile learning applications [16]

\subsection{Resut}

This process begins with the AR camera being dislodged. The AR camera then detects the marker used. Once the marker is detected, the app matches the marker with an existing dataset. When it matches the existing dataset then on the mobile screen will appear 3D objects above the marker. 3D object show process can be seen in Figure 2 .

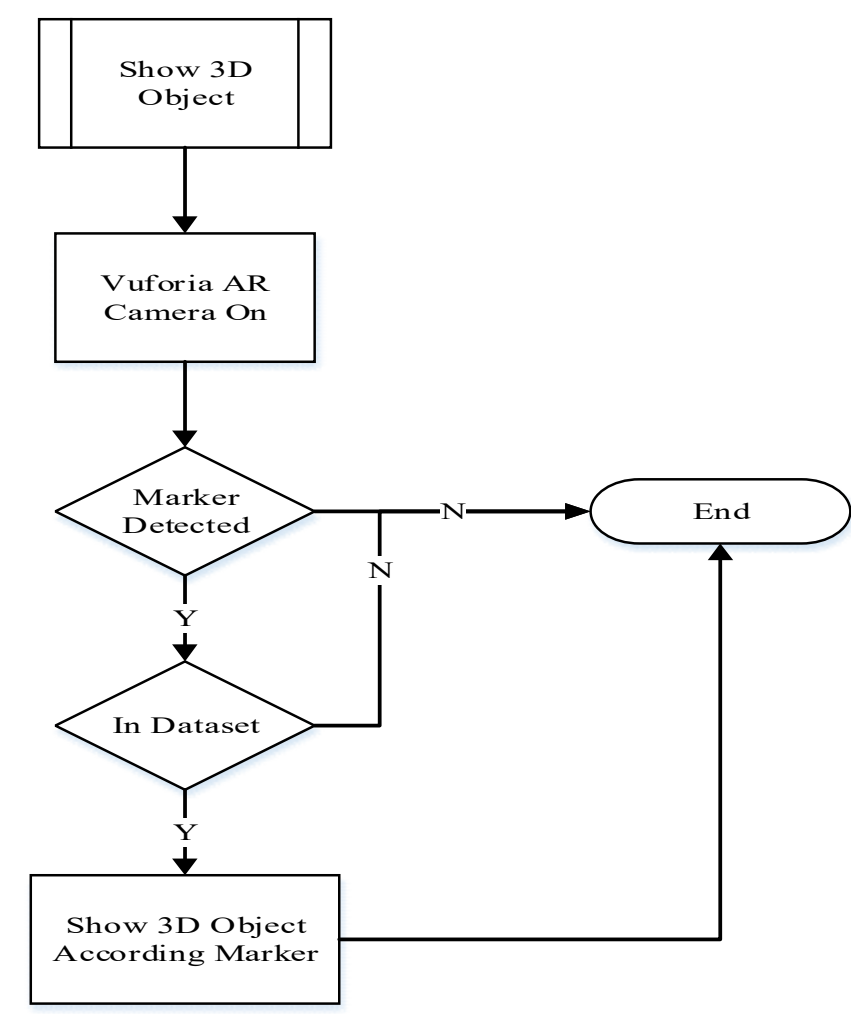

Figure 2. Flowchart show 3D object

The marker used in the "Chemical Bonding Application" is in the form of a hexagon card made simple but still interesting. Card design of marker used in this application can be seen in Figure 3. Card or marker designs are made different even though they contain one element in common because if the marker is made the same, the marker will detect one type even though the card is different and only bring up a $3 \mathrm{D}$ object. 


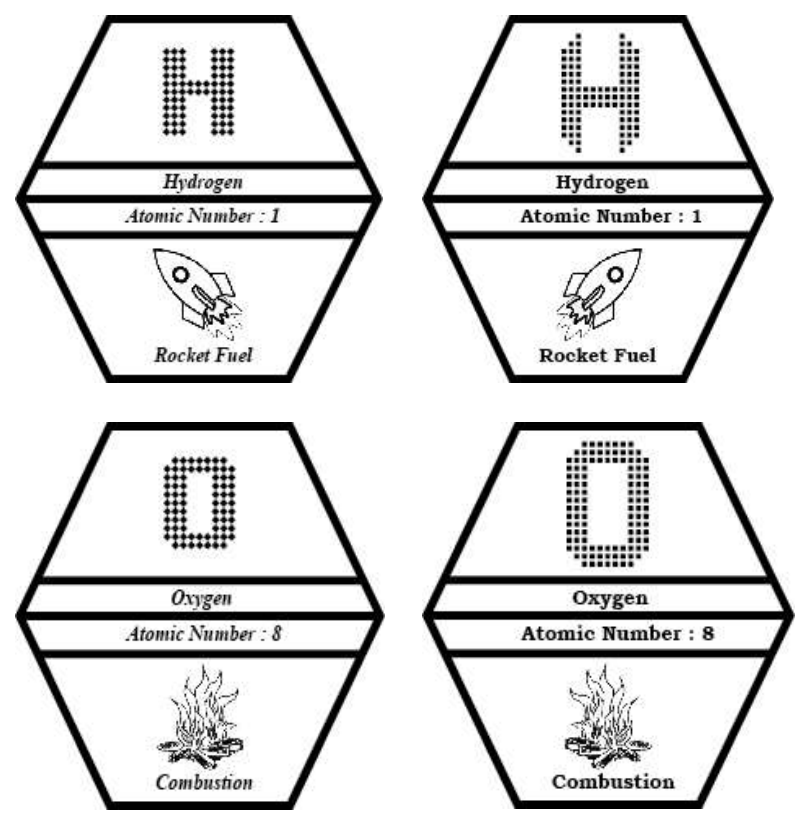

Figure 3. The design of marker

Android device testing is done by using Android 2 devices, among others, Sony Xperia M2 and Lenovo A7-30. Specifications devices can be seen in Table 1.

Table 1. Table Specifications

\begin{tabular}{|c|c|c|c|c|c|}
\hline Device & Operating System & Display Size & $\mathrm{CPU}$ & Memory & Camera Size \\
\hline Sony Xperia M2 & Android 5.1.1 & $\begin{array}{l}4.8 "(960 \times 540 \text { pixels } \& \\
16,777,216 \text {-colour TFT })\end{array}$ & $\begin{array}{c}\text { 1.2 GHz Qualcomm } \\
\text { MSM8926 Quad Core }\end{array}$ & 1 GB RAM & $8 \mathrm{MP}$ \\
\hline $\begin{array}{l}\text { Lenovo A7-30 } \\
\text { A3300 }\end{array}$ & Android 4.2.2 & $\begin{array}{l}7.0 "(600 \times 1024 \text { pixels } \& \\
\text { 16M colour TFT })\end{array}$ & 1.3 GHz Quad Core & 1 GB RAM & $2 \mathrm{MP}$ \\
\hline
\end{tabular}

The test is done by directing the mobile camera on the marker and then measured at what distance the marker can be recognized and can bring up the 3D object. Page view 3D object that can be selected by the user through the superbly specified point coordinates can be seen in Figure 4 and Figure 5 . Figure 4 shows the test results against the precision of 3D objects that appear using Sony Xperia M2 device. From the test can be obtained results that the 3D Object that appears has been in accordance with the marker.

The Figure 5 shows the test results against the precision of 3D objects that appear using Lenovo A730 device. From the test can be obtained results that the 3D Object that appears has been in accordance with the marker.

Testing the next stage is done to see if 3D Object can react with another 3D Object if the marker has entered a predetermined distance. The test is divided namely, conformity information presented for each element, testing of $43 \mathrm{D}$ objects that have a reaction. This test is performed to see the movement of four 3D Objects that have a reaction. This test is done by directing the camera on four different markers and having reactions to each other.

The Figure 6 is a test of 4 Object 3D that has a reaction using Sony Xperia M2 device. From the test results obtained that the $3 \mathrm{D}$ Object can react by moving and join the other $3 \mathrm{D}$ Object according to the relationship of the reaction. The testing of 4 Object 3D that has a reaction using Lenovo A7-30 devices. From the test results obtained that the $3 \mathrm{D}$ Object can react by moving and join the other $3 \mathrm{D}$ Object according to the relationship of the reaction can be seen Figure 7. 


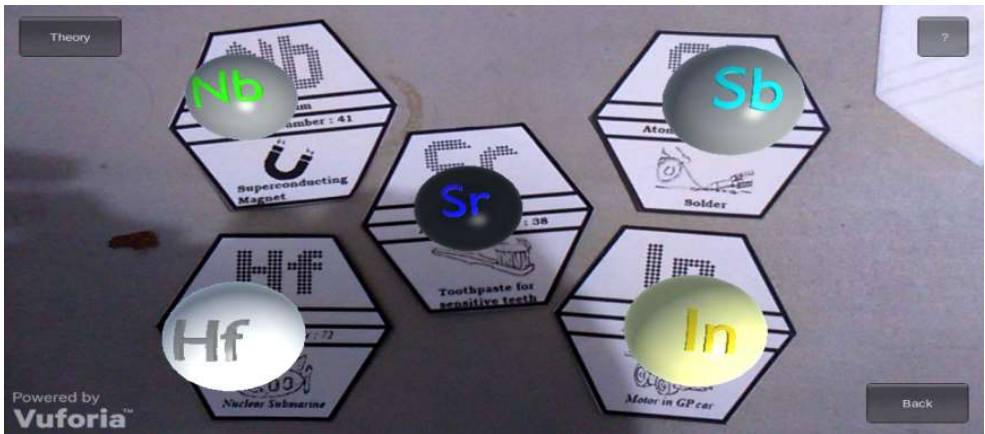

Figure 4. Test of 3D object xperia M2 object

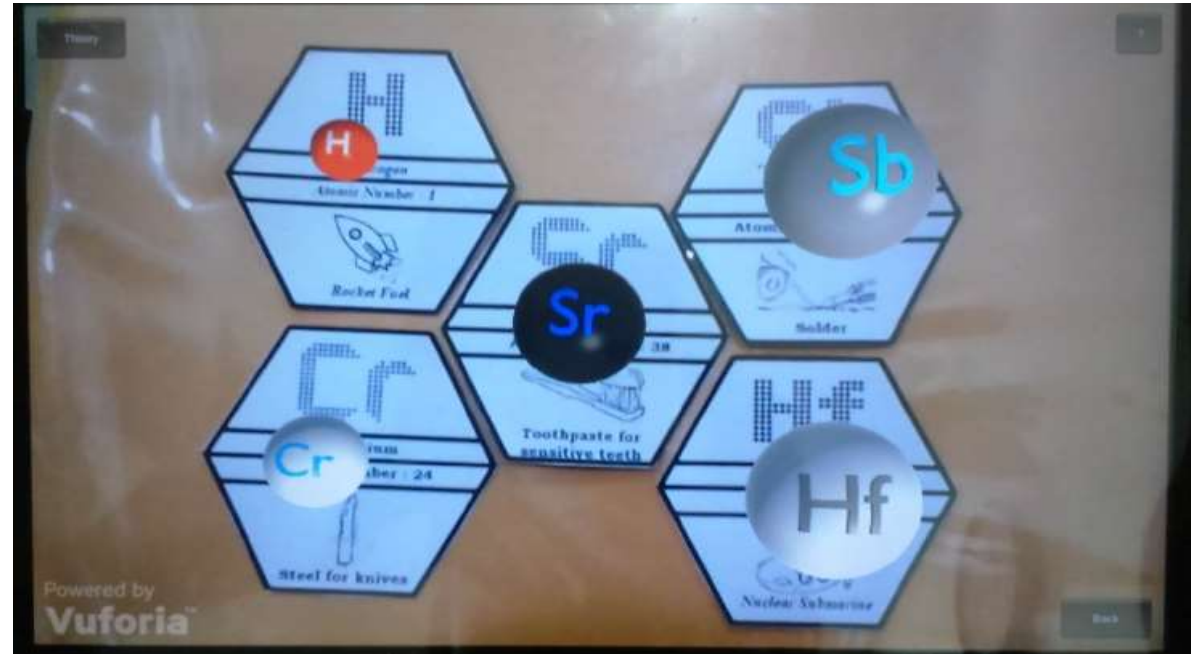

Figure 5. Test of 3D object lenovo A7-30 accuracy

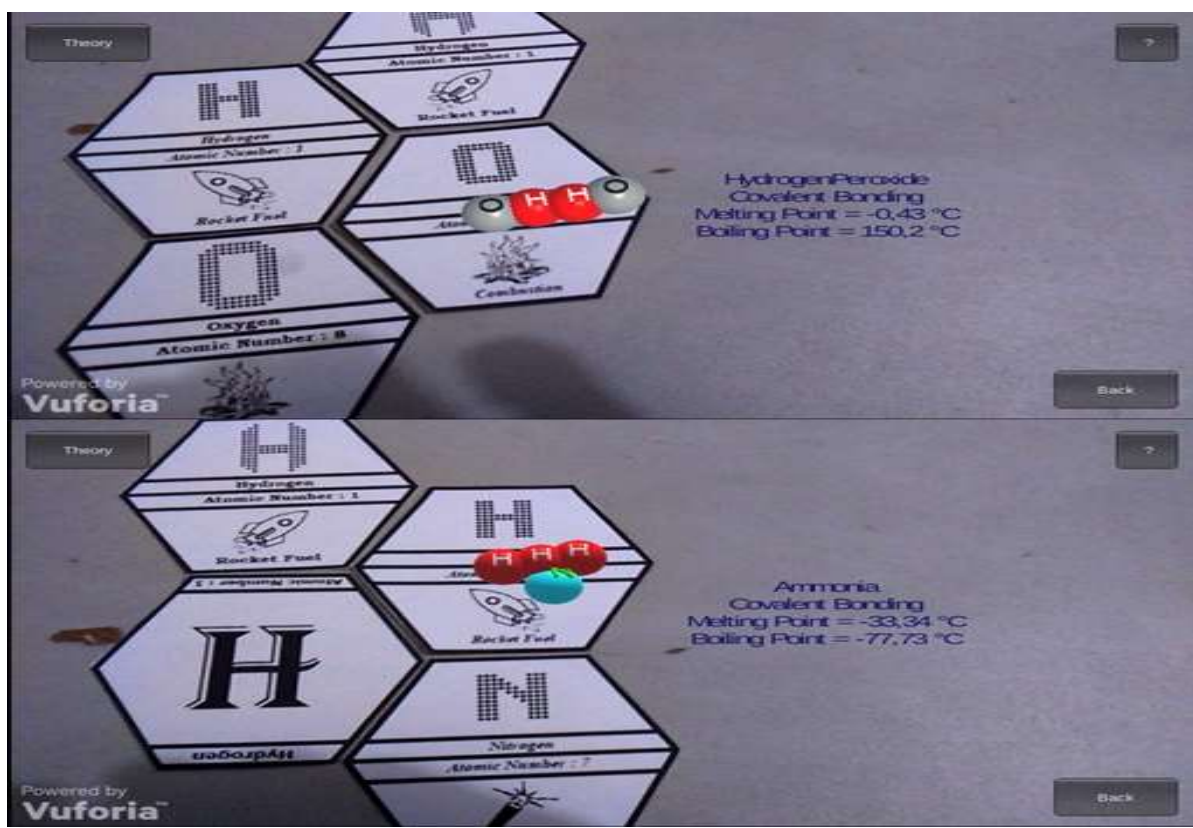

Figure 6. Testing the four object 3D with Sony Xperia M2 device 


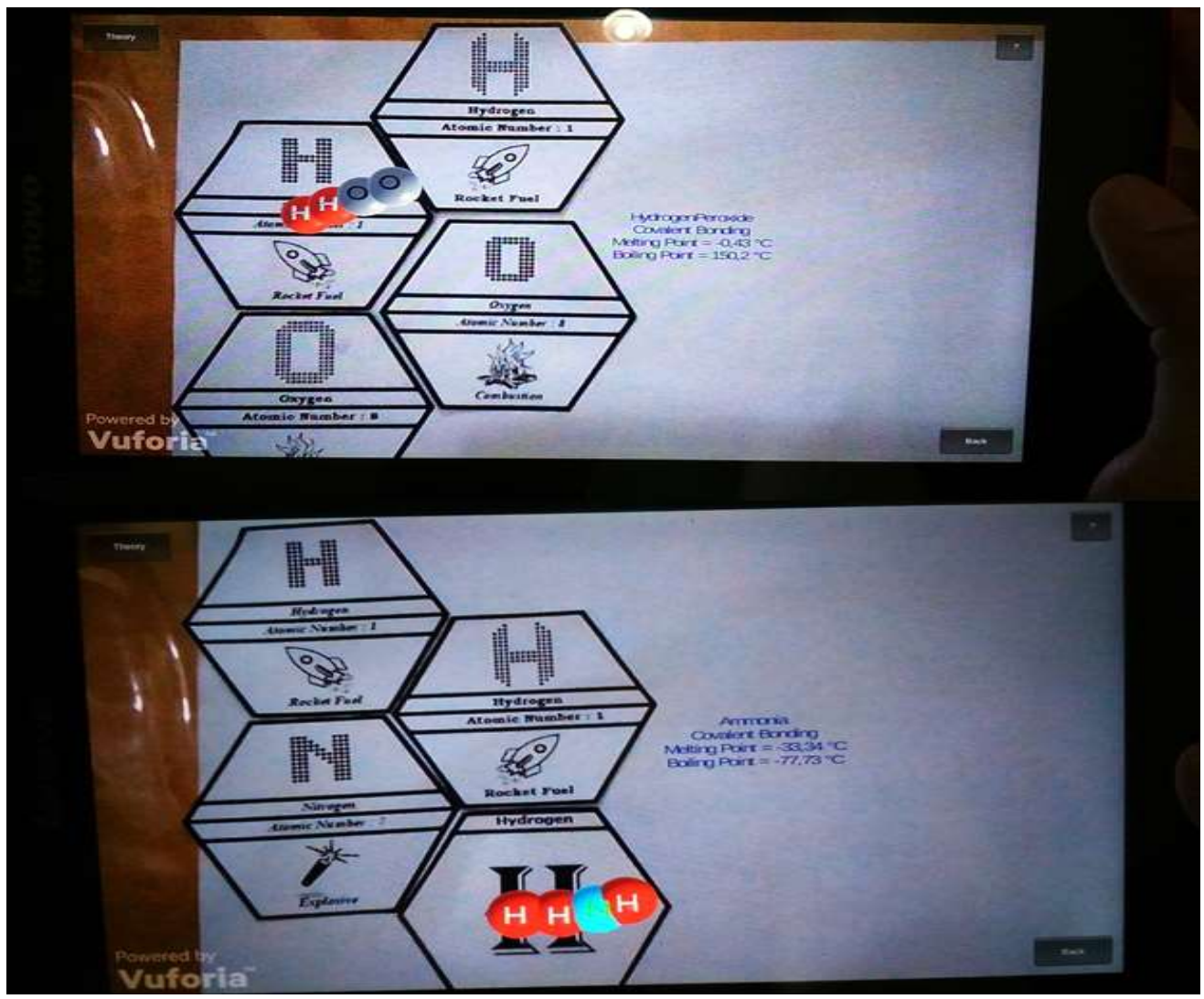

Figure 7. Testing the four Object 3D with lenovo A7-30 device

\section{CONCLUSION}

At the end of the design and development of application program for the chemical bonding application, some conclusions can be drawn through the test.

a. The Markers are made different from each other because one marker image can only be detected as a target. So to bring up more than one of the same elements requires markers with different shapes or images.

b. The marker detection by the mobile camera is running well, the marker is recognizable so as to bring up the corresponding 3D objects. Marker $\mathrm{H}$ raises the 3D element element $\mathrm{H}$.

c. The chemical bonding application can generate annotations for each element. Description of the element name, atomic number, mass number, oxidation number and the shape of the element.

d. Applications can run a $3 \mathrm{D}$ object pooling of elements that have a bond to form a compound.

\section{REFERENCES}

[1] Cai, Su. Xu Wang. Feng-Kuang Chiang, "A Case Study of Augmented Reality Simulation System Application in A Chemestry Course," Computer in Behavior, Volume 39, Elsevier, 2014.

[2] Sommerauer, Peter. Oliver Muller, "Augmented Reality in Informal Learning Environments: A Field Experiment in A Mathematics Exhibition," Computer \& Education, Volume 79, 2014

[3] Kose, Utku. Durmus Koc, "Suleyman Anil Yucesoy. An Augmented Reality Based Mobile Software to Support Learning Experiences in Computer Science Courses,” Procedia Computer Science, Volume 25. Elsevier, 2013.

[4] Cirulis, Arnis, "Kristaps Brigis Brigmanis, 3D Outdoor Augmented Reality for Architecture and Urban Planning," Procedia Computer Science, Volume 25, 2013.

[5] Azuma, Ronald T. "A Survey of Augmented Reality”. Presence : Teleoperators and Virtual Environtments, 1997.

[6] J. Carmigniani, B. Furht, M. Anisetti, P. Ceravolo, E. Damiani and M. Ivkovic. "Augmented Reality Technologies, Systems and Applications," Multimedia Tools and Applications, Vol. 51, No. 1, 2011, pp. 341-377. http://dx.doi.org/10.1007/s11042-010-0660-6, 2011.

[7] J. Carmigniani and B. Furht, 2011. "Augmented Reality: An Overview" In: J. Carmigniani and B. Furht, Eds., Hand-book of Augmented Reality, Springer, New York, pp. 3-46. http://dx.doi.org/10.1007/978-1-4614-0064-6_1, 2011. 
[8] J. Ford and T. Höllerer, 2008. "Augmented Reality and the Fu- ture of Virtual Workspaces," In: Handbook of Research on Virtual Workplaces and the New Nature of Business Practices, IGI Global, Santa Barbara, pp. 486502, 2008.

[9] A. Alkhamisi and M. Monowar, "Rise of Augmented Reality: Current and Future Application Areas," International Journal of Internet and Distributed Systems, Vol. 1 No. 4, 2013, pp. 25-34. doi: 10.4236/ijids.2013.14005, 2013.

[10] Teguh Martono, K, "Augmented Reality Sebagai Metafora Baru dalam Teknologi Interaksi Manusia dan Komputer," Jurnal Sistem Komputer, 1(2), 60-64, 2011.

[11] Safaat, N, "Pemrograman Aplikasi Mobile Smartphone dan Table PC Berbasis Android Revisi Kedua," Bandung: Informatika Bandung, 2014.

[12] Salbino. S, Buku Pintar Gadget Android untuk Pemula. Jakarta: Kunci Komunikasi, 2014.

[13] Teddy M, Andri Z., "Securing E-Mail Communication Using Hybrid Cryptosystem on Android-based Mobile Devices," TELKOMNIKA Indonesian Journal of Electrical Engineering, 10(2); 827-834, 2012.

[14] W3schools. AJAX Introduction, URL=http://www.w3schools.com/Ajax/ajax_intro.asp, 2016.

[15] Ahmad F, Sri D, Dieka R, "Location Based Service for Information Publication Using GPS On Android-Based Mobile Phone," Proceeding of International Conference on Electrical Engineering, Computer Science and Informatics (EECSI), 1(39); 190-197, 2014.

[16] Setiawan, A., Handojo, A., \& Hadi, R., Indonesian Culture Learning Application Based on Android. International Journal of Electrical and Computer Engineering, 7(1), 526, 2017.

\section{BIOGRAPHIES OF AUTHORS}

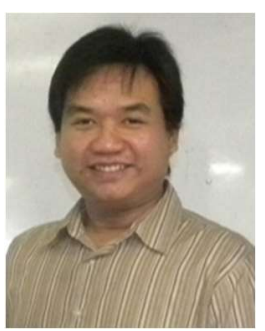

Alexander Setiawan-Obtained his Bachelor Computer degree in Informatics Engineering from Petra Christian University, Surabaya, Indonesia in 2003. He received his master, in Information Technology from Gadjah Mada University, Yogyakarta, Indonesia, in 2008. Now, he served as Assistant Professor and a lecturer in the Department of Informatics Engineering at Petra Christian University, Surabaya, Indonesia. His primary research interest is in software engineering, business intelligent, management information system, and human computer interaction.

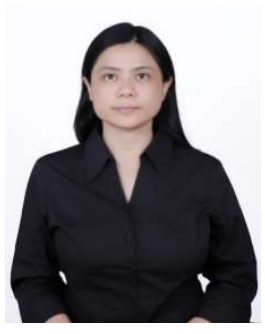

Silvia Rostianingsih - Obtained her Bachelor of Informatics Engineering degree in Informatics Department from Institute of Technology Sepuluh Nopember, Indonesia in 2001. She received her master, in Master of Technology Management from Institute of Technology Sepuluh Nopember, Indonesia, in 2004. Now, she served as Assistant Professor in Informatics Department at Petra Christian University, Indonesia. Her primary research interest is in database, business intelligent, and mobile device application.

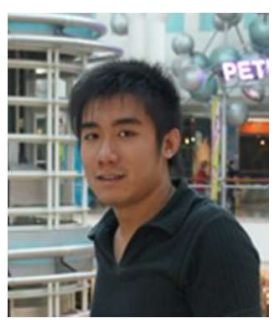

Timotius Reinaldo Widodo - Obtained his Bachelor computer degree in Informatics Department from Petra Christian University, Indonesia in 2016. 